\title{
Age and sex-specific associations of anthropometric measures of adiposity with blood pressure and hypertension in India: a cross-sectional study
}

\author{
Kevin Y. Taing ${ }^{1,2^{*}}$, Michael E. Farkouh ${ }^{3,4}$, Rahim Moineddin ${ }^{5,7}$, Jack V. Tu $u^{6,7,8}$ and Prabhat Jha ${ }^{1,2}$
}

\begin{abstract}
Background: A determinant of blood pressure is adiposity; however, there are uncertainties surrounding whether general or central adiposity is the more important determinant of blood pressure. Further, inconsistent results exist for the relationships of anthropometric measures with blood pressure and hypertension, and whether these relationships differ substantially by age and sex is unclear. We aimed to elucidate the associations of anthropometric measures of general and central adiposity with blood pressure and hypertension, and determine the effect of age and sex on these relationships.

Methods: We used cross-sectional data from the Centre for Global Health Research health check-up survey conducted during 2006-2007 of the general population in India ( $n=7$ 601; age 18-59 years). We examined the associations of anthropometric measures (body mass index, waist circumference, hip circumference, waist-hip ratio, waist-height ratio) with blood pressure components (systolic pressure, diastolic pressure, pulse pressure, mean arterial pressure, mid-blood pressure) and hypertension within four (18-29 years, 30-39 years, 40-49 years, 5059 years) age groups, by sex. We adjusted all analyses for education and location, with further adjustments, variously, for either a measure of central (waist circumference) or general (body mass index) adiposity.

Results: On average, every $5 \mathrm{~kg} / \mathrm{m}^{2}$ greater body mass index or $10 \mathrm{~cm}$ wider waist circumference was associated with a 5 and $4 \mathrm{mmHg}$ higher systolic blood pressure, respectively. When considered separately, each anthropometric measure was strongly and positively associated with most blood pressure components in all age groups, and for both sexes. However, with few exceptions, when considered jointly (body mass index adjusted for waist circumference), the associations of body mass index with blood pressure components and hypertension were greatly diminished for both sexes, and particularly in the $\geq 30$ years age groups. By contrast, further adjustment of waist circumference for body mass index did not materially alter the associations of waist circumference with blood pressure components and hypertension.
\end{abstract}

Conclusions: Our findings indicate that central adiposity, as assessed with anthropometric measures, may be a more important determinant of blood pressure and hypertension than general adiposity for adults in India.

Keywords: Age, Sex, Anthropometry, Body mass index, Waist circumference, Adiposity, Blood pressure, Hypertension, India

\footnotetext{
* Correspondence: kevin.taing@utoronto.ca

${ }^{1}$ Centre for Global Health Research, St. Michael's Hospital, Toronto, ON,

Canada

${ }^{2}$ Dalla Lana School of Public Health, University of Toronto, Toronto, ON,

Canada

Full list of author information is available at the end of the article
} 


\section{Background}

India is undergoing a rapid health transition with substantial increases in chronic non-communicable diseases, such as cardiovascular disease (CVD) [1, 2], whereby elevated blood pressure and hypertension are well-established risk factors [3-6]. High blood pressure accounts for the greatest proportion of deaths attributed to chronic disease risk factors in India [1], and recent estimates show that about $30 \%$ of the population is hypertensive [7]. In order to abate the burden of hypertension and related health outcomes, it is important to understand and establish the relationships between major risk factors for elevated blood pressure. However, studies examining these relationships are often from high income countries, thus the results may not be generalizable to low and middle-income countries (LMIC), such as India. In spite of the need for studies investigating the associations between risk factors for hypertension, there is limited reliable evidence from India and other LMICs.

A main determinant of blood pressure is adiposity [8-10], and various mechanisms have been proposed to link different body fat distributions to blood pressure and risk of hypertension $[9,10]$. However, despite the suggested mechanisms, there are uncertainties surrounding whether a general or central distribution of adiposity is more strongly associated with blood pressure. Anthropometric indices are often used as a proxy measure of adiposity. Broadly, these anthropometric measures of adiposity can be considered either a measure of general adiposity, such as the body mass index (BMI), or measures of central adiposity, such as waist circumference (WC), hip circumference (HC), and their ratios, waist-hip ratio (WHR) and waist-height ratio (WHtR). Similar to the uncertainties in proposed mechanisms, there are inconsistencies as to whether anthropometric measures of general or central adiposity are more strongly associated with blood pressure and hypertension [11-14]. In addition, considerable uncertainty exists regarding whether the strength of these associations differs substantially by age and sex.

Reliable assessment of the relationships of anthropometric measures with blood pressure and hypertension in India and other LMICs is of particular importance. Clarification of these associations will contribute additional evidence to aid in facilitating the allocation of resources for public health promotion and prevention of hypertension and CVD. Additionally, by improving our understanding of whether a simple measure of general or central adiposity is more strongly associated with blood pressure and hypertension may help focus screening efforts and risk stratification of clinical populations where the measurement of blood pressure is not feasible. However, most previous studies from India are small, from one region, provide conflicting evidence, and do not fully investigate the effect of age and sex on these relationships [11-14]. Indeed, there is a paucity of research from India that directly examines the association of commonly used anthropometric measures of adiposity with blood pressure and hypertension. Thus, these associations remain inadequately characterized. Furthermore, given the importance and potential differences in prognostic value of distinct blood pressure components [systolic blood pressure (SBP), diastolic blood pressure (DBP), pulse pressure, mean arterial pressure, mid-blood pressure $[4,5]$, it is equally important to elucidate the relationships between anthropometric measures and continuous blood pressure components, in addition to hypertension.

We therefore examine the independent and joint association of anthropometric measures of general and central adiposity with various blood pressure components and hypertension, and determine the effect of age and sex on these relationships in a sample of adults from the general population of India.

\section{Methods \\ Study design, setting and participants}

We conducted a cross-sectional study investigating the relationships between anthropometric measures of adiposity, blood pressure, and hypertension in India. In order to aid in the characterization of disease and death of individuals, households and communities, the Centre for Global Health Research health check-up survey of the general population of India was conducted during 2006 and 2007. Participants were recruited in four states (Andhra Pradesh, Karnataka, Gujarat, Rajasthan) and two union territories (Chandigarh, Delhi) from randomly selected sampling units (within the Registrar General of India's “Sample Registration System"), which were based on the 1991 census [15]. We used data from adults 18-59 years of age from the health check-up survey in our analyses $(n=7$ 784). Of these participants, 119 were excluded because of pregnancy, and 64 due to missing data for either level of education, SBP, DBP, height, weight, $\mathrm{WC}$, or $\mathrm{HC}$.

\section{Study data sources}

Field teams consisting of trained surveyors visited houses identified in their respective sampling units to obtain consent and enroll participants (surveyors made at least three visits to each household). All data collection was done in the household following a standardized protocol. In addition to physical measurements, participants were interviewed to obtain information on demographic, socioeconomic, lifestyle characteristics and antihypertensive medication use. 
Blood pressure and anthropometric measurement

Blood pressure was measured twice at heart level, in a seated position after $5 \mathrm{~min}$ of rest using the Omron (Kyoto, Japan) digital automatic blood pressure monitor. SBP and DBP were calculated as the average of the two readings, pulse pressure as the difference between SBP and DBP, mean arterial pressure as a third SBP plus two thirds DBP, and mid-blood pressure as half SBP plus half DBP. Hypertension was defined as SBP $\geq 140 \mathrm{mmHg}$ or $\mathrm{DBP} \geq 90 \mathrm{mmHg}$, or reported use of antihypertensive medication.

Height was measured with a measuring tape to the nearest $0.1 \mathrm{~cm}$. Individuals were requested to stand upright without footwear, with their head, back, buttocks and heels against a wall, arms at their sides, feet together and eyes directed forward. Height was then measured as the distance from the top of the head to the ground. Weight was measured on a hard level surface to the nearest $0.1 \mathrm{~kg}$ using the KRUPS (New Delhi, India) weighing scale, without footwear and only light clothing. WC was measured to the nearest $0.1 \mathrm{~cm}$ using a measuring tape. Measurements were taken at the midway point between the lower rib and iliac crest without clothing when possible. If participant did not want to move aside clothing, it was indicated and measurements were taken above light clothing. HC was measured to the nearest $0.1 \mathrm{~cm}$ using a measuring tape. Measurements were taken at the point yielding the maximum circumference over the buttocks with individuals wearing light clothing. In order to account for clothing, $1 \mathrm{~cm}$ was subtracted from measured values. BMI was calculated as weight in kilograms divided by the square of height in meters. WHR was calculated as WC in centimeters divided by $\mathrm{HC}$ in centimeters, and WHtR as WC in centimeters divided by height in centimeters.

\section{Statistical analysis}

We performed all analyses separately for men and women. We calculated Pearson's partial correlation coefficients for the relationships between anthropometric measures (BMI, WC, HC, WHR, WHtR) and blood pressure (SBP, DBP, pulse pressure, mean arterial pressure, mid-blood pressure), adjusted for age and location. We used multiple linear regression models to quantify the association between each anthropometric measure with each continuous blood pressure component, and Poisson regression models to quantify the relationship between each anthropometric measure and hypertension. We evaluated age as an effect measure modifier by including age and anthropometric measure interaction terms in regression models, and by examining the stratum-specific estimates by age groups (18-29 years, $30-39$ years, $40-49$ years, and $50-59$ years).
We estimated the means of each blood pressure component, and calculated the prevalence ratios (PR) for hypertension per sub-group specific standard deviation (SD) change in anthropometric measures within each age group. 235 individuals (3\% of total) who reported current use of antihypertensive medication were excluded from the continuous blood pressure analyses. We used two models for all analyses, model 1 adjusted for level of education (illiterate, primary school, middle school, secondary school, college) and location (11 categories, representing rural/urban area of each state and union territory), and in model 2 additional adjustments were made for either WC or BMI. Further adjustment for alcohol (nondrinker, current drinker) and tobacco (nonuser, current user) use did not materially affect these estimates (results not presented). We performed all statistical analyses using SAS version 9.3 (SAS Institute, Cary, NC, USA), and provide estimates with their respective $95 \%$ confidence intervals $(\mathrm{CI})$.

\section{Results}

Distribution of the mean (SD) anthropometric measures, blood pressure components, and hypertension prevalence by sex and age groups are presented in Table 1 . The mean age of participants was 40 (11) years. On average, blood pressure increased with age for both sexes, with the exception of DBP, which increased until the fourth decade and remained relatively constant between the fourth and fifth decade. Mean blood pressure (regardless of blood pressure component) was higher for men than women in all age groups. Similarly, hypertension prevalence was higher for men than women, except in the 50-59 years age group where it was comparable.

The means for all anthropometric measures were lowest in the youngest age group (18-29 years) and increased in older age groups for both men and women. BMI and HC were similar between both sexes in the youngest age group, and slightly higher among women in the older age groups. By contrast, mean WC and WHR were higher $(\sim 6-7 \mathrm{~cm}$ and $0.08-0.1$ respectively) for men than women across all age groups. There were no discernible differences for mean WHtR between the sexes.

The intercorrelations of anthropometric measures and blood pressure components are shown in Table 2 . Among the correlations, the weakest were consistently observed between anthropometric measures and pulse pressure.

\section{Anthropometric measures and continuous blood pressure} The changes in SBP and DBP [mmHg per SD $(95 \% \mathrm{CI})]$ for each anthropometric measure by sex and age groups are presented in Tables 3 and 4. On average, every $5 \mathrm{~kg} /$ $\mathrm{m}^{2}$ greater BMI or $10 \mathrm{~cm}$ wider $\mathrm{WC}$ was associated with 
Table 1 Distribution of anthropometric measures and blood pressure $(n=7601)$

\begin{tabular}{|c|c|c|c|c|c|c|c|c|c|c|c|c|c|c|c|c|c|c|c|c|c|c|}
\hline \multirow{3}{*}{$\frac{\text { Age }}{\text { Male }}$} & \multirow{3}{*}{ No. } & \multicolumn{2}{|c|}{ BMI $\left(\mathrm{kg} / \mathrm{m}^{2}\right)$} & \multicolumn{2}{|c|}{$W C(\mathrm{~cm})$} & \multicolumn{2}{|c|}{$\mathrm{HC}(\mathrm{cm})$} & \multicolumn{2}{|l|}{ WHR } & \multicolumn{2}{|c|}{$\mathrm{WH} \mathrm{tR}$} & \multicolumn{2}{|c|}{ SBP (mmHg) } & \multicolumn{2}{|c|}{$\mathrm{DBP}(\mathrm{mmHg})$} & \multicolumn{2}{|c|}{$\mathrm{PP}(\mathrm{mmHg})$} & \multicolumn{2}{|c|}{ MAP (mmHg) } & \multicolumn{2}{|c|}{$\mathrm{MBP}(\mathrm{mmHg})$} & \multirow[t]{2}{*}{ HTN (\%) } \\
\hline & & & & & & & & & & & & & & & & & & & & & & \\
\hline & & & & & & & & & & & & & & & & & & & & & & \\
\hline $18-29$ & 1620 & 20.6 & (3.6) & 71.2 & (9.8) & 84.7 & (7.3) & 0.84 & $(0.066)$ & 0.43 & $(0.058)$ & 123.2 & (11.8) & 74.7 & $(9.5)$ & 48.4 & (8.8) & 90.9 & $(9.4)$ & 99.0 & (9.7) & $187(11.5)$ \\
\hline $30-39$ & 967 & 21.9 & $(4.2)$ & 77.2 & (11.8) & 87.0 & (8.1) & 0.88 & $(0.072)$ & 0.46 & $(0.067)$ & 124.3 & $(13.5)$ & 78.8 & (10.5) & 45.5 & $(8.2)$ & 94.0 & $(10.9)$ & 101.6 & $(11.4)$ & $163(16.9)$ \\
\hline $40-49$ & 640 & 22.7 & $(4.4)$ & 80.8 & (12.4) & 88.0 & $(8.2)$ & 0.92 & $(0.079)$ & 0.49 & $(0.071)$ & 129.7 & $(18.9)$ & 82.5 & (12.3) & 47.2 & $(10.9)$ & 98.3 & (13.9) & 106.1 & $(15.0)$ & $210(32.8)$ \\
\hline $50-59$ & 519 & 22.7 & (4.6) & 81.9 & (13.4) & 87.7 & (8.5) & 0.93 & $(0.084)$ & 0.50 & $(0.078)$ & 133.8 & (20.0) & 82.6 & (11.8) & 51.2 & (13.0) & 99.7 & (13.7) & 108.2 & $(15.1)$ & $212(40.9)$ \\
\hline Total & 3746 & 21.6 & $(4.2)$ & 75.9 & $(12.2)$ & 86.3 & (8.0) & 0.88 & $(0.081)$ & 0.46 & $(0.072)$ & 126.1 & (15.4) & 78.2 & (11.1) & 47.9 & $(9.9)$ & 94.2 & $(11.8)$ & 102.1 & (12.5) & 772 (20.6) \\
\hline Female & & & & & & & & & & & & & & & & & & & & & & \\
\hline $18-29$ & 1608 & 20.4 & $(4.0)$ & 63.9 & $(9.2)$ & 84.2 & (8.1) & 0.76 & $(0.065)$ & 0.42 & $(0.060)$ & 112.6 & $(11.2)$ & 72.7 & (8.8) & 40.0 & $(7.5)$ & 86.0 & $(9.0)$ & 92.7 & (9.3) & $71(4.4)$ \\
\hline 30-39 & 992 & 22.5 & $(4.9)$ & 69.9 & (11.5) & 88.5 & (9.7) & 0.79 & $(0.071)$ & 0.46 & $(0.075)$ & 116.4 & (13.4) & 76.5 & (9.9) & 39.9 & $(7.7)$ & 89.8 & (10.6) & 96.4 & $(11.2)$ & $122(12.3)$ \\
\hline $40-49$ & 737 & 23.8 & $(5.3)$ & 73.9 & (12.3) & 90.9 & (10.3) & 0.81 & $(0.078)$ & 0.49 & $(0.079)$ & 123.8 & $(18.2)$ & 79.9 & (10.7) & 43.9 & (11.5) & 94.5 & (12.6) & 101.8 & (13.8) & 185 \\
\hline $50-59$ & 518 & 23.8 & (5.6) & 75.7 & (13.3) & 91.3 & (11.3) & 0.83 & $(0.083)$ & 0.50 & $(0.087)$ & 132.1 & (21.9) & 81.6 & $(11.2)$ & 50.5 & (15.5) & 98.4 & (13.8) & 106.8 & (15.6) & 202 (39.0) \\
\hline Total & 3855 & 22.0 & (4.9) & 68.9 & $(12.0)$ & 87.5 & (9.9) & 0.78 & $(0.076)$ & 0.45 & $(0.079)$ & 118.3 & (16.5) & 76.2 & (10.4) & 42.1 & (10.5) & 90.3 & (11.8) & 97.3 & (12.8) & $580(15.1)$ \\
\hline
\end{tabular}

Values presented as mean (SD), unless indicated ${ }^{\mathrm{a} N o}$. (\%) hypertensive. BMI body mass index, WC waist circumference, $H C$ hip circumference, WHR waist-hip ratio, WHtR waist-height ratio, SBP systolic blood pressure, $D B P$ diastolic blood pressure, $P P$ pulse pressure, MAP mean arterial pressure, MBP mid-blood pressure, $H T N$ hypertension 
Table 2 Pearson partial correlation coefficients adjusted for age and location ( $n=7$ 366)

\begin{tabular}{|c|c|c|c|c|c|c|c|c|c|c|}
\hline & & WC & $\mathrm{HC}$ & WHR & $\mathrm{WHtR}$ & SBP & DBP & $\mathrm{PP}$ & MAP & $\mathrm{MBP}$ \\
\hline \multirow[t]{2}{*}{ BMI } & Male: & 0.88 & 0.84 & 0.62 & 0.89 & 0.27 & 0.34 & 0.06 & 0.33 & 0.32 \\
\hline & Female: & 0.86 & 0.85 & 0.47 & 0.87 & 0.26 & 0.34 & $0.05^{*}$ & 0.33 & 0.31 \\
\hline \multirow[t]{2}{*}{ WC } & & Male: & 0.85 & 0.82 & 0.96 & 0.27 & 0.35 & $0.04^{*}$ & 0.34 & 0.33 \\
\hline & & Female: & 0.82 & 0.74 & 0.96 & 0.27 & 0.34 & 0.07 & 0.33 & 0.32 \\
\hline \multirow[t]{2}{*}{$\mathrm{HC}$} & & & Male: & 0.40 & 0.76 & 0.26 & 0.32 & $0.05^{*}$ & 0.31 & 0.30 \\
\hline & & & Female: & 0.24 & 0.76 & 0.22 & 0.31 & $0.02^{* *}$ & 0.29 & 0.27 \\
\hline \multirow[t]{2}{*}{ WHR } & & & & Male: & 0.84 & 0.20 & 0.27 & $0.01^{* *}$ & 0.26 & 0.24 \\
\hline & & & & Female: & 0.75 & 0.21 & 0.23 & 0.09 & 0.23 & 0.23 \\
\hline \multirow[t]{2}{*}{ WHtR } & & & & & Male: & 0.26 & 0.34 & $0.03^{* *}$ & 0.33 & 0.31 \\
\hline & & & & & Female: & 0.28 & 0.34 & 0.08 & 0.34 & 0.32 \\
\hline \multirow[t]{2}{*}{ SBP } & & & & & & Male: & 0.75 & 0.71 & 0.91 & 0.96 \\
\hline & & & & & & Female: & 0.76 & 0.76 & 0.92 & 0.96 \\
\hline \multirow[t]{2}{*}{ DBP } & & & & & & & Male: & 0.07 & 0.96 & 0.91 \\
\hline & & & & & & & Female: & 0.14 & 0.95 & 0.91 \\
\hline \multirow[t]{2}{*}{ PP } & & & & & & & & Male: & 0.36 & 0.47 \\
\hline & & & & & & & & Female: & 0.43 & 0.54 \\
\hline \multirow[t]{2}{*}{ MAP } & & & & & & & & & Male: & 0.99 \\
\hline & & & & & & & & & Female: & 0.99 \\
\hline
\end{tabular}

Correlations exclude those on antihypertensive medication. All correlations coefficients significant at $p<0.0001$, unless indicated ${ }^{*} p<0.05,{ }^{* *} p>0.05$. BMI body mass index, WC waist circumference, $H C$ hip circumference, WHR waist-hip ratio, WHtR waist-height ratio, SBP systolic blood pressure, $D B P$ diastolic blood pressure, $P P$ pulse pressure, MAP mean arterial pressure, $M B P$ mid-blood pressure

a 5 and $4 \mathrm{mmHg}$ higher $\mathrm{SBP}$, and a 4 and $3 \mathrm{mmHg}$ higher DBP, respectively. Independently, each measure was strongly and positively associated with SBP and DBP for both sexes across all age groups (model 1). However, after additional adjustment for WC or BMI, the association of each anthropometric measure with SBP and DBP were markedly different, and largely dependent on the age group (model 2).

Among men in the 18-29 and 30-39 years age groups, the association between WC and SBP was slightly weaker than the relationship between BMI and SBP. By contrast, the association between $\mathrm{WC}$ and DBP was stronger than the relationship between BMI and DBP. Further, in the 30-39 years age group, the association between BMI and DBP was largely diminished (3.44 to $0.52 \mathrm{mmHg}$ ) with the additional adjustment for WC. In comparison, additional adjustment for BMI did not materially alter the relation between WC and DBP. Among women in the 18-29 years age group, BMI remained significantly associated with both SBP and DBP after adjusting for WC. However, further adjustment for BMI greatly reduced the strength of association of $\mathrm{WC}$ with SBP and DBP, from $3.05 \mathrm{mmHg}$ to $1.01 \mathrm{mmHg}$ and $2.40 \mathrm{mmHg}$ to $0.53 \mathrm{mmHg}$, respectively.

The additional adjustment for WC greatly attenuated the relationship of BMI with SBP and DBP in the two older age groups (40-49 years, 50-59 years) for both men and women. By contrast, the association of WC with SBP and DBP for men, and WHtR and SBP, and WC and DBP for women were only slightly attenuated and remained significant $(p<0.05)$ after further adjustment for BMI. Overall, the relationship of HC and WHR with SBP and DBP diminished with additional adjustment for BMI for both sexes across all age groups. Comparably, the associations of WHtR with SBP and DBP were also weakened after adjustment for BMI, with the exception of WHtR with SBP in the 50-59 years age group for both sexes.

The analyses of the relationships of anthropometric measures with pulse pressure, mean arterial pressure and mid-blood pressure can be found in Tables 5, 6 and 7. The associations between anthropometric measures and pulse pressure were weaker than those with the other blood pressure components. There was a significant $(p<0.05)$ negative association between WHtR and pulse pressure after adjustment for BMI for men in the 18-29 $[-1.53(-2.43,-0.64)]$ and $30-39[-1.25(-2.45,-0.06)]$ years age groups (Table 5$)$. This negative association may be due, in part, to the stronger relationship between WHtR and DBP [18-29 years: 1.69 (0.80, 2.57), 3039 years: $3.22(1.81,4.64)]$, than WHtR and SBP [1829 years: $0.16(-0.97,1.28), 30-39$ years: $1.97(0.10,3.84)$ ] in those age groups. Greater increases in DBP than SBP per SD higher WHtR would decrease the difference 
Table 3 Mean differences in systolic and diastolic blood pressure for anthropometric measures among men $(n=3664)$

\begin{tabular}{|c|c|c|c|c|c|}
\hline \multirow[b]{4}{*}{ Measurement (SD) } & \multirow[b]{4}{*}{ Age } & \multicolumn{4}{|c|}{ mmHg per SD $(95 \% \mathrm{Cl})$} \\
\hline & & \multicolumn{2}{|c|}{ Systolic blood pressure } & \multicolumn{2}{|c|}{ Diastolic blood pressure } \\
\hline & & Model 1 & Model 2 & Model 1 & Model 2 \\
\hline & & & & & \\
\hline \multicolumn{6}{|l|}{ Body Mass Index ${ }^{a}$} \\
\hline$\left(3.6 \mathrm{~kg} / \mathrm{m}^{2}\right)$ & $18-29$ & $4.07(3.51,4.62)$ & $2.44(1.36,3.53)$ & $3.70(3.26,4.14)$ & $1.59(0.74,2.45)$ \\
\hline$\left(4.2 \mathrm{~kg} / \mathrm{m}^{2}\right)$ & $30-39$ & $4.44(3.58,5.31)$ & $2.42(0.64,4.20)$ & $3.44(2.77,4.10)$ & $0.52(-0.83,1.86)$ \\
\hline$\left(4.4 \mathrm{~kg} / \mathrm{m}^{2}\right)$ & $40-49$ & $5.39(3.83,6.94)$ & $2.11(-1.39,5.60)$ & $4.14(3.15,5.12)$ & $1.09(-1.10,3.28)$ \\
\hline$\left(4.6 \mathrm{~kg} / \mathrm{m}^{2}\right)$ & $50-59$ & $4.37(2.34,6.40)$ & $0.47(-3.60,4.55)$ & $3.50(2.33,4.66)$ & $0.89(-1.44,3.23)$ \\
\hline \multicolumn{6}{|c|}{ Waist Circumference ${ }^{b}$} \\
\hline$(9.8 \mathrm{~cm})$ & $18-29$ & $3.96(3.41,4.51)$ & $1.87(0.80,2.95)$ & $3.79(3.36,4.22)$ & $2.43(1.58,3.28)$ \\
\hline$(11.8 \mathrm{~cm})$ & $30-39$ & $4.39(3.53,5.25)$ & $2.29(0.53,4.06)$ & $3.75(3.10,4.40)$ & $3.30(1.97,4.63)$ \\
\hline$(12.4 \mathrm{~cm})$ & $40-49$ & $5.55(4.00,7.11)$ & $3.67(0.17,7.16)$ & $4.38(3.40,5.36)$ & $3.41(1.21,5.60)$ \\
\hline$(13.4 \mathrm{~cm})$ & $50-59$ & $4.91(2.89,6.93)$ & $4.50(0.41,8.59)$ & $3.79(2.63,4.95)$ & $3.01(0.66,5.35)$ \\
\hline \multicolumn{6}{|l|}{ Hip Circumference ${ }^{b}$} \\
\hline$(7.3 \mathrm{~cm})$ & $18-29$ & $4.03(3.46,4.60)$ & $1.87(0.89,2.85)$ & $3.62(3.17,4.08)$ & $1.59(0.81,2.36)$ \\
\hline$(8.1 \mathrm{~cm})$ & $30-39$ & $4.10(3.21,4.98)$ & $1.14(-0.47,2.74)$ & $3.21(2.54,3.89)$ & $1.04(-0.18,2.26)$ \\
\hline$(8.2 \mathrm{~cm})$ & $40-49$ & $4.72(3.12,6.33)$ & $0.32(-2.63,3.28)$ & $3.52(2.50,4.54)$ & $-0.10(-1.96,1.76)$ \\
\hline$(8.5 \mathrm{~cm})$ & $50-59$ & $4.62(2.60,6.64)$ & $3.19(-0.41,6.80)$ & $3.70(2.54,4.86)$ & $2.56(0.49,4.62)$ \\
\hline \multicolumn{6}{|l|}{ Waist-Hip Ratio ${ }^{\text {b }}$} \\
\hline$(0.066)$ & $18-29$ & $2.49(1.94,3.04)$ & $0.37(-0.28,1.02)$ & $2.54(2.10,2.98)$ & $0.75(0.23,1.26)$ \\
\hline$(0.072)$ & $30-39$ & $3.40(2.55,4.24)$ & $1.14(0.05,2.22)$ & $3.21(2.58,3.84)$ & $1.88(1.06,2.69)$ \\
\hline$(0.079)$ & $40-49$ & $4.49(3.00,5.98)$ & $1.95(-0.03,3.93)$ & $3.74(2.80,4.68)$ & $2.03(0.79,3.27)$ \\
\hline$(0.084)$ & $50-59$ & $3.70(1.77,5.63)$ & $1.80(-0.68,4.28)$ & $2.68(1.56,3.80)$ & $0.97(-0.46,2.40)$ \\
\hline \multicolumn{6}{|l|}{ Waist-Height Ratiob } \\
\hline$(0.058)$ & $18-29$ & $3.52(2.97,4.07)$ & $0.16(-0.97,1.28)$ & $3.56(3.13,3.99)$ & $1.69(0.80,2.57)$ \\
\hline$(0.067)$ & $30-39$ & $4.25(3.40,5.09)$ & $1.97(0.10,3.84)$ & $3.63(2.99,4.26)$ & $3.22(1.81,4.64)$ \\
\hline$(0.071)$ & $40-49$ & $5.28(3.76,6.80)$ & $2.95(-0.64,6.55)$ & $4.19(3.24,5.14)$ & $3.02(0.76,5.28)$ \\
\hline$(0.078)$ & $50-59$ & $5.19(3.21,7.17)$ & $6.44(2.12,10.76)$ & $3.78(2.64,4.92)$ & $3.38(0.90,5.87)$ \\
\hline
\end{tabular}

Estimates exclude those on antihypertensive medication. Model 1, estimates from multiple linear regression, adjusted for education and location. Model 2, model

1 plus additional adjustments for ${ }^{\mathrm{a}}$ Waist circumference or ${ }^{\mathrm{b}}$ Body mass index. $S D$ standard deviation, $\mathrm{Cl}$ confidence interval

between SBP and DBP, thus lowering pulse pressure. The associations of anthropometric measures with mean arterial and mid-blood pressure were similar to those observed with SBP and DBP, which may be partly due to the high correlations between these blood pressure components. Of note, the relationship between $\mathrm{WC}$ and mid-blood pressure was stronger than the association between BMI and mid-blood pressure for men across all age groups, and for women in the $\geq 30$ years age groups.

\section{Anthropometric measures and hypertension}

Figures 1 and 2 show the PRs (95\% CI) for hypertension according to age groups for men and women, respectively. Regardless of the anthropometric measure of adiposity, all were significantly $(p<0.05)$ associated with hypertension when considered separately (model 1 ). Overall, the associations of central adiposity measures (mainly WC or WHtR) with hypertension were slightly stronger than between BMI and hypertension for both sexes. The relationships of $\mathrm{HC}$ and WHR with hypertension were somewhat weaker than those observed with WC and WHtR.

After additional adjustment for WC, the relationship between BMI and hypertension was largely diminished across all age groups, particularly for men (model 2). Conversely, with a few exceptions, the relationship of WC and WHtR with hypertension remained predominantly unaffected after the additional adjustment for BMI. However, for women in the youngest (18-29 years) age group, additional adjustment for BMI reduced the association of WC and WHtR with hypertension. In addition, although not statistically significant $(p=0.37)$, there was a slight negative association between $\mathrm{HC}$ and hypertension for women in the youngest age group. 
Table 4 Mean differences in systolic and diastolic blood pressure for anthropometric measures among women $(n=3702)$

\begin{tabular}{|c|c|c|c|c|c|}
\hline \multirow[b]{4}{*}{ Measurement (SD) } & \multirow[b]{4}{*}{ Age } & \multicolumn{4}{|c|}{ mmHg per SD $(95 \% \mathrm{Cl})$} \\
\hline & & \multicolumn{2}{|c|}{ Systolic blood pressure } & \multicolumn{2}{|c|}{ Diastolic blood pressure } \\
\hline & & Model 1 & Model 2 & Model 1 & Model 2 \\
\hline & & & & & \\
\hline \multicolumn{6}{|l|}{ Body Mass Index ${ }^{a}$} \\
\hline$\left(4.0 \mathrm{~kg} / \mathrm{m}^{2}\right)$ & $18-29$ & $3.32(2.78,3.86)$ & $2.46(1.44,3.47)$ & $2.69(2.27,3.12)$ & $2.24(1.45,3.03)$ \\
\hline$\left(4.9 \mathrm{~kg} / \mathrm{m}^{2}\right)$ & $30-39$ & $5.40(4.55,6.25)$ & $2.60(0.85,4.36)$ & $4.79(4.18,5.40)$ & $2.73(1.48,3.98)$ \\
\hline$\left(5.3 \mathrm{~kg} / \mathrm{m}^{2}\right)$ & $40-49$ & $5.03(3.65,6.42)$ & $-0.05(-2.60,2.49)$ & $4.26(3.48,5.05)$ & $0.79(-0.65,2.23)$ \\
\hline$\left(5.6 \mathrm{~kg} / \mathrm{m}^{2}\right)$ & $50-59$ & $3.76(1.70,5.83)$ & $0.70(-3.21,4.62)$ & $2.95(1.91,4.00)$ & $1.00(-0.98,2.98)$ \\
\hline \multicolumn{6}{|c|}{ Waist Circumference ${ }^{b}$} \\
\hline$(9.2 \mathrm{~cm})$ & $18-29$ & $3.05(2.52,3.59)$ & $1.01(0.01,2.00)$ & $2.40(1.97,2.82)$ & $0.53(-0.25,1.31)$ \\
\hline$(11.5 \mathrm{~cm})$ & $30-39$ & $5.47(4.62,6.32)$ & $3.19(1.44,4.95)$ & $4.74(4.13,5.35)$ & $2.35(1.10,3.60)$ \\
\hline$(12.3 \mathrm{~cm})$ & $40-49$ & $6.01(4.64,7.39)$ & $6.06(3.50,8.62)$ & $4.81(4.04,5.59)$ & $4.14(2.69,5.59)$ \\
\hline$(13.3 \mathrm{~cm})$ & $50-59$ & $4.15(2.12,6.19)$ & $3.56(-0.31,7.43)$ & $3.12(2.08,4.15)$ & $2.28(0.32,4.24)$ \\
\hline \multicolumn{6}{|l|}{ Hip Circumference ${ }^{b}$} \\
\hline$(8.1 \mathrm{~cm})$ & $18-29$ & $2.89(2.33,3.44)$ & $0.41(-0.55,1.37)$ & $2.43(2.00,2.86)$ & $0.60(-0.15,1.35)$ \\
\hline$(9.7 \mathrm{~cm})$ & $30-39$ & $4.51(3.65,5.38)$ & $-0.58(-2.28,1.13)$ & $4.07(3.45,4.69)$ & $-0.24(-1.46,0.98)$ \\
\hline$(10.3 \mathrm{~cm})$ & $40-49$ & $4.69(3.28,6.09)$ & $1.07(-1.83,3.96)$ & $3.97(3.17,4.77)$ & $0.91(-0.74,2.55)$ \\
\hline$(11.3 \mathrm{~cm})$ & $50-59$ & $3.01(1.00,5.01)$ & $-0.35(-4.17,3.47)$ & $2.80(1.78,3.81)$ & $1.32(-0.61,3.26)$ \\
\hline \multicolumn{6}{|l|}{ Waist-Hip Ratio ${ }^{\text {b }}$} \\
\hline$(0.065)$ & $18-29$ & $1.91(1.37,2.45)$ & $0.49(-0.10,1.09)$ & $1.33(0.91,1.76)$ & $0.12(-0.34,0.59)$ \\
\hline$(0.071)$ & $30-39$ & $4.24(3.39,5.09)$ & $2.05(1.09,3.02)$ & $3.50(2.88,4.13)$ & $1.47(0.78,2.15)$ \\
\hline$(0.078)$ & $40-49$ & $4.95(3.59,6.31)$ & $3.44(1.95,4.93)$ & $3.64(2.85,4.43)$ & $2.22(1.38,3.07)$ \\
\hline$(0.083)$ & $50-59$ & $3.37(1.38,5.36)$ & $2.23(0.04,4.42)$ & $1.87(0.84,2.90)$ & $0.80(-0.32,1.91)$ \\
\hline \multicolumn{6}{|l|}{ Waist-Height Ratiob } \\
\hline$(0.060)$ & $18-29$ & $3.06(2.53,3.59)$ & $1.08(0.04,2.12)$ & $2.45(2.03,2.86)$ & $0.72(-0.09,1.53)$ \\
\hline$(0.075)$ & $30-39$ & $5.31(4.48,6.14)$ & $3.01(1.23,4.80)$ & $4.62(4.02,5.21)$ & $2.24(0.97,3.51)$ \\
\hline$(0.079)$ & $40-49$ & $5.76(4.44,7.09)$ & $5.75(3.24,8.26)$ & $4.53(3.78,5.28)$ & $3.62(2.20,5.04)$ \\
\hline$(0.087)$ & $50-59$ & $4.39(2.39,6.38)$ & $4.97(0.92,9.03)$ & $2.97(1.96,3.99)$ & $1.96(-0.10,4.03)$ \\
\hline
\end{tabular}

Estimates exclude those on antihypertensive medication. Model 1, estimates from multiple linear regression, adjusted for education and location. Model 2, model 1 plus additional adjustments for ${ }^{\mathrm{a}}$ Waist circumference or ${ }^{\mathrm{b}}$ Body mass index. $S D$ standard deviation, $\mathrm{Cl}$ confidence interval

\section{Discussion}

In our study, central adiposity, as assessed by WC was more strongly associated with the majority of blood pressure components and hypertension than general adiposity, as assessed by BMI. In addition, the relationship of WC with blood pressure and hypertension was largely independent of BMI. Our findings suggest that central adiposity may be a more important determinant of blood pressure and hypertension than general adiposity for adults in India.

Irrespective of the anthropometric measure of adiposity, when considered separately each was strongly and positively associated with SBP, DBP, and hypertension. Our results showed that, on average, every $5 \mathrm{~kg} / \mathrm{m}^{2}$ greater BMI was associated with a $5 \mathrm{mmHg}$ higher SBP and a $4 \mathrm{mmHg}$ higher DBP, which is similar to results from a large study of a mainly European population [16].
However, it is well known that there are considerable differences in body fat distribution according to ethnicity. South Asians tend to have more abdominal adiposity when compared with Europeans [17]. Moreover, independent of sex, greater abdominal adiposity, whether visceral or subcutaneous is associated with many deleterious metabolic risk factors, including higher SBP, DBP and odds of hypertension [18]. Thus, anthropometric measures that capture central body fat distribution may be more informative for describing adverse health outcomes in a South Asian population.

With few exceptions, WC or WHtR was the measure with the strongest relation to nearly all blood pressure components independent of BMI. Among men in the younger (18-29 and 30-39 years) age groups, the relation between WC and SBP was somewhat weaker than between BMI and SBP. Nevertheless, in the same age 
Table 5 Mean differences in pulse pressure for anthropometric measures ( $n=7$ 366)

\begin{tabular}{|c|c|c|c|c|c|c|}
\hline \multirow[b]{3}{*}{ Age } & \multirow[b]{3}{*}{ Measurement (SD) } & \multicolumn{2}{|c|}{$\begin{array}{l}\text { Male } \\
\mathrm{mmHg} \text { per SD }(95 \% \mathrm{Cl})\end{array}$} & \multirow[b]{3}{*}{ Measurement (SD) } & \multicolumn{2}{|c|}{$\begin{array}{l}\text { Female } \\
\text { mmHg per SD }(95 \% \text { Cl) }\end{array}$} \\
\hline & & Model 1 & Model 2 & & Model 1 & Model 2 \\
\hline & & & & & & \\
\hline & Body Mass Index & & & Body Mass Index & & \\
\hline $18-29$ & $\left(3.6 \mathrm{~kg} / \mathrm{m}^{2}\right)$ & $0.37(-0.07,0.81)$ & $0.85(-0.02,1.72)$ & $\left(4.0 \mathrm{~kg} / \mathrm{m}^{2}\right)$ & $0.63(0.25,1.00)$ & $0.22(-0.48,0.92)$ \\
\hline $30-39$ & $\left(4.2 \mathrm{~kg} / \mathrm{m}^{2}\right)$ & $1.01(0.45,1.56)$ & $1.90(0.76,3.04)$ & $\left(4.9 \mathrm{~kg} / \mathrm{m}^{2}\right)$ & $0.61(0.08,1.14)$ & $-0.13(-1.23,0.97)$ \\
\hline $40-49$ & $\left(4.4 \mathrm{~kg} / \mathrm{m}^{2}\right)$ & $1.25(0.31,2.19)$ & $1.02(-1.09,3.12)$ & $\left(5.3 \mathrm{~kg} / \mathrm{m}^{2}\right)$ & $0.77(-0.13,1.66)$ & $-0.84(-2.51,0.83)$ \\
\hline \multirow[t]{2}{*}{$50-59$} & $\left(4.6 \mathrm{~kg} / \mathrm{m}^{2}\right)$ & $0.87(-0.48,2.23)$ & $-0.42(-3.16,2.32)$ & $\left(5.6 \mathrm{~kg} / \mathrm{m}^{2}\right)$ & $0.81(-0.69,2.31)$ & $-0.29(-3.15,2.56)$ \\
\hline & Waist Circumference ${ }^{\mathrm{b}}$ & & & Waist Circumference ${ }^{b}$ & & \\
\hline $18-29$ & $(9.8 \mathrm{~cm})$ & $0.17(-0.27,0.61)$ & $-0.56(-1.42,0.31)$ & $(9.2 \mathrm{~cm})$ & $0.66(0.29,1.03)$ & $0.48(-0.22,1.17)$ \\
\hline $30-39$ & $(11.8 \mathrm{~cm})$ & $0.63(0.08,1.19)$ & $-1.01(-2.14,0.12)$ & $(11.5 \mathrm{~cm})$ & $0.73(0.20,1.26)$ & $0.84(-0.25,1.94)$ \\
\hline $40-49$ & $(12.4 \mathrm{~cm})$ & $1.17(0.23,2.11)$ & $0.26(-1.85,2.37)$ & $(12.3 \mathrm{~cm})$ & $1.20(0.30,2.10)$ & $1.92(0.24,3.60)$ \\
\hline \multirow[t]{2}{*}{$50-59$} & $(13.4 \mathrm{~cm})$ & $1.13(-0.23,2.48)$ & $1.49(-1.25,4.24)$ & $(13.3 \mathrm{~cm})$ & $1.04(-0.45,2.52)$ & $1.28(-1.54,4.11)$ \\
\hline & Hip Circumference ${ }^{b}$ & & & Hip Circumference ${ }^{b}$ & & \\
\hline $18-29$ & $(7.3 \mathrm{~cm})$ & $0.40(-0.05,0.86)$ & $0.28(-0.50,1.07)$ & $(8.1 \mathrm{~cm})$ & $0.46(0.08,0.84)$ & $-0.19(-0.86,0.47)$ \\
\hline $30-39$ & $(8.1 \mathrm{~cm})$ & $0.88(0.32,1.44)$ & $0.10(-0.93,1.12)$ & $(9.7 \mathrm{~cm})$ & $0.44(-0.08,0.97)$ & $-0.33(-1.40,0.73)$ \\
\hline $40-49$ & $(8.2 \mathrm{~cm})$ & $1.20(0.24,2.15)$ & $0.43(-1.35,2.20)$ & $(10.3 \mathrm{~cm})$ & $0.71(-0.19,1.62)$ & $0.16(-1.71,2.03)$ \\
\hline \multirow[t]{2}{*}{$50-59$} & $(8.5 \mathrm{~cm})$ & $0.92(-0.43,2.28)$ & $0.64(-1.78,3.06)$ & $(11.3 \mathrm{~cm})$ & $0.21(-1.24,1.67)$ & $-1.67(-4.45,1.11)$ \\
\hline & Waist-Hip Ratio ${ }^{\text {b }}$ & & & Waist-Hip Ratio ${ }^{b}$ & & \\
\hline $18-29$ & $(0.066)$ & $-0.05(-0.48,0.37)$ & $-0.38(-0.90,0.14)$ & $(0.065)$ & $0.57(0.21,0.94)$ & $0.37(-0.04,0.78)$ \\
\hline $30-39$ & $(0.072)$ & $0.19(-0.35,0.72)$ & $-0.74(-1.43,-0.05)$ & $(0.071)$ & $0.74(0.22,1.25)$ & $0.59(-0.02,1.19)$ \\
\hline $40-49$ & $(0.079)$ & $0.75(-0.15,1.64)$ & $-0.08(-1.27,1.12)$ & $(0.078)$ & $1.31(0.44,2.19)$ & $1.22(0.24,2.19)$ \\
\hline \multirow[t]{2}{*}{$50-59$} & $(0.084)$ & $1.02(-0.27,2.30)$ & $0.83(-0.84,2.49)$ & $(0.083)$ & $1.50(0.06,2.94)$ & $1.43(-0.16,3.03)$ \\
\hline & Waist-Height Ratio ${ }^{b}$ & & & Waist-Height Ratio ${ }^{b}$ & & \\
\hline $18-29$ & $(0.058)$ & $-0.04(-0.47,0.39)$ & $-1.53(-2.43,-0.64)$ & $(0.060)$ & $0.62(0.25,0.98)$ & $0.36(-0.36,1.08)$ \\
\hline $30-39$ & $(0.067)$ & $0.62(0.08,1.16)$ & $-1.25(-2.45,-0.06)$ & $(0.075)$ & $0.69(0.18,1.21)$ & $0.77(-0.34,1.89)$ \\
\hline $40-49$ & $(0.071)$ & $1.09(0.18,2.00)$ & $-0.07(-2.24,2.10)$ & $(0.079)$ & $1.23(0.36,2.10)$ & $2.13(0.49,3.77)$ \\
\hline $50-59$ & $(0.078)$ & $1.41(0.07,2.74)$ & $3.06(0.15,5.97)$ & $(0.087)$ & $1.41(-0.04,2.87)$ & $3.01(0.05,5.97)$ \\
\hline
\end{tabular}

Estimates exclude those on antihypertensive medication. Model 1, estimates from multiple linear regression, adjusted for education and location. Model 2, model 1 plus additional adjustments for ${ }^{a}$ Waist circumference or ${ }^{b}$ Body mass index. SD standard deviation, $\mathrm{Cl}$ confidence interval

groups, WC was more strongly associated with DBP than BMI. Indeed, DBP may be a more important component of blood pressure than SBP in these age groups; since many studies have shown the significance of DBP over SBP as the main driver of vascular risk in young adults [19]. Moreover, WC was also more strongly associated with mid-blood pressure than BMI for men across all age groups. This finding could be of particular importance, given that mid-blood pressure has been shown to be a more informative component than either SBP or DBP alone to predict vascular mortality [5].

Apart from the youngest (18-29 years) age group, the associations between anthropometric measures and blood pressure among women were similar to those for men. The observed difference for younger women may be explained, at least in part, by the marked heterogeneity in body fat distribution between men and women, and differences in the rate of abdominal fat accumulation. For instance, women generally have a higher percentage of body fat with a more peripheral distribution as compared to men, who have a more central distribution [20]. Hence, a measure of general adiposity, such as the BMI, may better reflect this peripheral fat distribution and be somewhat more strongly related to SBP and DBP than WC in young women. However, independent of body weight, an increase in abdominal adiposity occurs throughout life, with rates of gain being faster for men than women [21]. This difference in abdominal adiposity gain may provide an explanation for why the independent association of WC or WHtR with SBP and DBP was observed across all age groups for men, and not until older ( $\geq 30$ years) age groups for women.

The associations of anthropometric measures with hypertension were, for the most part, comparable to 
Table 6 Mean differences in mean arterial pressure for anthropometric measures $(n=7366)$

\begin{tabular}{|c|c|c|c|c|c|c|}
\hline \multirow[b]{3}{*}{ Age } & \multirow[b]{3}{*}{ Measurement (SD) } & \multicolumn{2}{|c|}{$\begin{array}{l}\text { Male } \\
\text { mmHg per SD }(95 \% \text { Cl) }\end{array}$} & \multirow[b]{3}{*}{ Measurement (SD) } & \multicolumn{2}{|c|}{$\begin{array}{l}\text { Female } \\
\text { mmHg per SD }(95 \% \text { Cl) }\end{array}$} \\
\hline & & Model 1 & Model 2 & & Model 1 & Model 2 \\
\hline & & & & & & \\
\hline & Body Mass Index ${ }^{a}$ & & & Body Mass Index ${ }^{a}$ & & \\
\hline $18-29$ & $\left(3.6 \mathrm{~kg} / \mathrm{m}^{2}\right)$ & $3.82(3.39,4.25)$ & $1.88(1.03,2.72)$ & $\left(4.0 \mathrm{~kg} / \mathrm{m}^{2}\right)$ & $2.90(2.47,3.33)$ & $2.31(1.51,3.11)$ \\
\hline $30-39$ & $\left(4.2 \mathrm{~kg} / \mathrm{m}^{2}\right)$ & $3.77(3.08,4.46)$ & $1.15(-0.25,2.56)$ & $\left(4.9 \mathrm{~kg} / \mathrm{m}^{2}\right)$ & $4.99(4.34,5.65)$ & $2.69(1.34,4.03)$ \\
\hline $40-49$ & $\left(4.4 \mathrm{~kg} / \mathrm{m}^{2}\right)$ & $4.55(3.43,5.67)$ & $1.43(-1.08,3.93)$ & $\left(5.3 \mathrm{~kg} / \mathrm{m}^{2}\right)$ & $4.52(3.58,5.46)$ & $0.51(-1.20,2.22)$ \\
\hline \multirow[t]{2}{*}{$50-59$} & $\left(4.6 \mathrm{~kg} / \mathrm{m}^{2}\right)$ & $3.79(2.42,5.15)$ & $0.75(-1.99,3.49)$ & $\left(5.6 \mathrm{~kg} / \mathrm{m}^{2}\right)$ & $3.22(1.94,4.51)$ & $0.90(-1.53,3.33)$ \\
\hline & Waist Circumference ${ }^{b}$ & & & Waist Circumference ${ }^{b}$ & & \\
\hline $18-29$ & $(9.8 \mathrm{~cm})$ & $3.85(3.42,4.27)$ & $2.24(1.41,3.08)$ & $(9.2 \mathrm{~cm})$ & $2.61(2.19,3.04)$ & $0.69(-0.10,1.48)$ \\
\hline $30-39$ & $(11.8 \mathrm{~cm})$ & $3.96(3.29,4.64)$ & $2.97(1.57,4.36)$ & $(11.5 \mathrm{~cm})$ & $4.98(4.33,5.64)$ & $2.63(1.29,3.97)$ \\
\hline $40-49$ & $(12.4 \mathrm{~cm})$ & $4.77(3.66,5.89)$ & $3.49(0.99,6.00)$ & $(12.3 \mathrm{~cm})$ & $5.21(4.29,6.13)$ & $4.78(3.06,6.50)$ \\
\hline \multirow[t]{2}{*}{$50-59$} & $(13.4 \mathrm{~cm})$ & $4.16(2.80,5.52)$ & $3.51(0.76,6.25)$ & $(13.3 \mathrm{~cm})$ & $3.46(2.20,4.73)$ & $2.70(0.30,5.11)$ \\
\hline & Hip Circumference ${ }^{b}$ & & & Hip Circumference ${ }^{b}$ & & \\
\hline $18-29$ & $(7.3 \mathrm{~cm})$ & $3.76(3.31,4.20)$ & $1.68(0.92,2.45)$ & $(8.1 \mathrm{~cm})$ & $2.58(2.14,3.02)$ & $0.54(-0.23,1.30)$ \\
\hline $30-39$ & $(8.1 \mathrm{~cm})$ & $3.51(2.81,4.21)$ & $1.07(-0.20,2.34)$ & $(9.7 \mathrm{~cm})$ & $4.22(3.55,4.88)$ & $-0.35(-1.66,0.96)$ \\
\hline $40-49$ & $(8.2 \mathrm{~cm})$ & $3.92(2.76,5.08)$ & $0.04(-2.09,2.17)$ & $(10.3 \mathrm{~cm})$ & $4.21(3.26,5.16)$ & $0.96(-0.99,2.92)$ \\
\hline \multirow[t]{2}{*}{$50-59$} & $(8.5 \mathrm{~cm})$ & $4.01(2.65,5.37)$ & $2.77(0.34,5.19)$ & $(11.3 \mathrm{~cm})$ & $2.87(1.62,4.12)$ & $0.77(-1.61,3.14)$ \\
\hline & Waist-Hip Ratio & & & Waist-Hip Ratio ${ }^{\text {b }}$ & & \\
\hline $18-29$ & $(0.066)$ & $2.53(2.09,2.96)$ & $0.62(0.11,1.13)$ & $(0.065)$ & $1.53(1.09,1.96)$ & $0.25(-0.23,0.72)$ \\
\hline 30-39 & $(0.072)$ & $3.27(2.61,3.94)$ & $1.63(0.78,2.48)$ & $(0.071)$ & $3.75(3.08,4.41)$ & $1.66(0.92,2.40)$ \\
\hline $40-49$ & $(0.079)$ & $3.99(2.92,5.07)$ & $2.00(0.58,3.42)$ & $(0.078)$ & $4.07(3.14,5.00)$ & $2.63(1.63,3.63)$ \\
\hline \multirow[t]{2}{*}{$50-59$} & $(0.084)$ & $3.02(1.72,4.33)$ & $1.24(-0.43,2.92)$ & $(0.083)$ & $2.37(1.12,3.62)$ & $1.28(-0.09,2.64)$ \\
\hline & Waist-Height Ratio ${ }^{b}$ & & & Waist-Height Ratio ${ }^{b}$ & & \\
\hline $18-29$ & $(0.058)$ & $3.55(3.12,3.97)$ & $1.18(0.30,2.05)$ & $(0.060)$ & $2.65(2.23,3.07)$ & $0.84(0.01,1.67)$ \\
\hline $30-39$ & $(0.067)$ & $3.83(3.17,4.50)$ & $2.81(1.33,4.28)$ & $(0.075)$ & $4.85(4.21,5.49)$ & $2.50(1.13,3.86)$ \\
\hline $40-49$ & $(0.071)$ & $4.55(3.46,5.64)$ & $3.00(0.42,5.58)$ & $(0.079)$ & $4.94(4.05,5.83)$ & $4.33(2.64,6.02)$ \\
\hline $50-59$ & $(0.078)$ & $4.25(2.92,5.59)$ & $4.40(1.49,7.31)$ & $(0.087)$ & $3.44(2.20,4.68)$ & $2.97(0.44,5.49)$ \\
\hline
\end{tabular}

Estimates exclude those on antihypertensive medication. Model 1, estimates from multiple linear regression, adjusted for education and location. Model 2, model

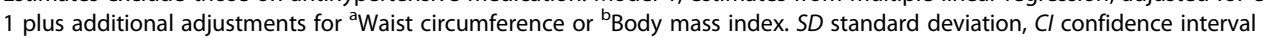

those observed with continuous blood pressure. A slight negative (albeit not statistically significant) relationship was present between $\mathrm{HC}$ and hypertension after adjusting for BMI among women in the youngest age group. This may be due, in part, to the protective effects of an increased $\mathrm{HC}$. A larger $\mathrm{HC}$ for a given BMI may be indicative of increased gluteofemoral fat, which has been shown to be independently associated with a better metabolic profile, and decreased odds of diabetes, dyslipidemia, and hypertension [22, 23]. Furthermore, it may influence blood pressure through direct effects on vascular health, whereby increased gluteofemoral fat is associated with lower arterial stiffness and aortic calcification [22].

Relative to the other anthropometric measures considered in our study, the association of WHR with all blood pressure components and hypertension was weak. The comparative differences in central body fat distribution may not be indicated by the WHR. For example, a similar WHR can be obtained by having both a large WC and $\mathrm{HC}$ or a small WC and HC. Moreover, differences in abdominal fat, specifically visceral adiposity may not be aptly reflected by changes in WHR [24]. This may explain, to some extent, the weaker associations found between WHR, blood pressure and hypertension. In comparison, after adjusting for BMI the association of WHtR with hypertension, although attenuated, was stronger than with $\mathrm{HC}$ and WHR for both sexes, especially for the oldest (50-59 years) age group. Indeed, our results suggest that WHtR may be of particular relevance in older ( $\geq 50$ years of age) adults. On average, in later adulthood after peak height is reached, there is a reduction of height with age [25]. Additionally, it has been shown that adult height is negatively associated 
Table 7 Mean differences in mid-blood pressure for anthropometric measures ( $n=7$ 366)

\begin{tabular}{|c|c|c|c|c|c|c|}
\hline \multirow[b]{3}{*}{ Age } & \multirow[b]{3}{*}{ Measurement (SD) } & \multicolumn{2}{|c|}{$\begin{array}{l}\text { Male } \\
\text { mmHg per SD }(95 \% \text { Cl) }\end{array}$} & \multirow[b]{3}{*}{ Measurement (SD) } & \multicolumn{2}{|c|}{$\begin{array}{l}\text { Female } \\
\text { mmHg per SD }(95 \% \text { Cl) }\end{array}$} \\
\hline & & Model 1 & Model 2 & & Model 1 & Model 2 \\
\hline & & & & & & \\
\hline & Body Mass Index ${ }^{a}$ & & & Body Mass Index ${ }^{a}$ & & \\
\hline $18-29$ & $\left(3.6 \mathrm{~kg} / \mathrm{m}^{2}\right)$ & $3.88(3.43,4.33)$ & $2.02(1.15,2.89)$ & $\left(4.0 \mathrm{~kg} / \mathrm{m}^{2}\right)$ & $3.01(2.56,3.45)$ & $2.35(1.51,3.18)$ \\
\hline $30-39$ & $\left(4.2 \mathrm{~kg} / \mathrm{m}^{2}\right)$ & $3.94(3.22,4.66)$ & $1.47(0.00,2.94)$ & $\left(4.9 \mathrm{~kg} / \mathrm{m}^{2}\right)$ & $5.10(4.40,5.79)$ & $2.67(1.24,4.09)$ \\
\hline $40-49$ & $\left(4.4 \mathrm{~kg} / \mathrm{m}^{2}\right)$ & $4.76(3.54,5.98)$ & $1.60(-1.12,4.31)$ & $\left(5.3 \mathrm{~kg} / \mathrm{m}^{2}\right)$ & $4.65(3.61,5.68)$ & $0.37(-1.53,2.26)$ \\
\hline \multirow[t]{2}{*}{$50-59$} & $\left(4.6 \mathrm{~kg} / \mathrm{m}^{2}\right)$ & $3.93(2.43,5.44)$ & $0.68(-2.34,3.71)$ & $\left(5.6 \mathrm{~kg} / \mathrm{m}^{2}\right)$ & $3.36(1.91,4.81)$ & $0.85(-1.90,3.60)$ \\
\hline & Waist Circumference ${ }^{b}$ & & & Waist Circumference ${ }^{b}$ & & \\
\hline $18-29$ & $(9.8 \mathrm{~cm})$ & $3.88(3.43,4.32)$ & $2.15(1.28,3.02)$ & $(9.2 \mathrm{~cm})$ & $2.72(2.28,3.17)$ & $0.77(-0.05,1.59)$ \\
\hline $30-39$ & $(11.8 \mathrm{~cm})$ & $4.07(3.36,4.78)$ & $2.80(1.34,4.26)$ & $(11.5 \mathrm{~cm})$ & $5.11(4.42,5.80)$ & $2.77(1.35,4.19)$ \\
\hline $40-49$ & $(12.4 \mathrm{~cm})$ & $4.97(3.76,6.18)$ & $3.54(0.82,6.26)$ & $(12.3 \mathrm{~cm})$ & $5.41(4.39,6.43)$ & $5.10(3.20,7.01)$ \\
\hline \multirow[t]{2}{*}{$50-59$} & $(13.4 \mathrm{~cm})$ & $4.35(2.85,5.85)$ & $3.75(0.72,6.79)$ & $(13.3 \mathrm{~cm})$ & $3.64(2.20,5.07)$ & $2.92(0.20,5.64)$ \\
\hline & Hip Circumference ${ }^{b}$ & & & Hip Circumference ${ }^{b}$ & & \\
\hline $18-29$ & $(7.3 \mathrm{~cm})$ & $3.83(3.36,4.29)$ & $1.73(0.94,2.52)$ & $(8.1 \mathrm{~cm})$ & $2.66(2.20,3.12)$ & $0.50(-0.29,1.30)$ \\
\hline $30-39$ & $(8.1 \mathrm{~cm})$ & $3.66(2.92,4.39)$ & $1.09(-0.24,2.42)$ & $(9.7 \mathrm{~cm})$ & $4.29(3.58,5.00)$ & $-0.41(-1.79,0.98)$ \\
\hline $40-49$ & $(8.2 \mathrm{~cm})$ & $4.12(2.87,5.38)$ & $0.11(-2.19,2.42)$ & $(10.3 \mathrm{~cm})$ & $4.33(3.28,5.38)$ & $0.99(-1.17,3.15)$ \\
\hline \multirow[t]{2}{*}{$50-59$} & $(8.5 \mathrm{~cm})$ & $4.16(2.66,5.66)$ & $2.88(0.20,5.55)$ & $(11.3 \mathrm{~cm})$ & $2.90(1.49,4.32)$ & $0.49(-2.20,3.18)$ \\
\hline & Waist-Hip Ratio & & & Waist-Hip Ratio ${ }^{\text {b }}$ & & \\
\hline $18-29$ & $(0.066)$ & $2.52(2.06,2.97)$ & $0.56(0.03,1.08)$ & $(0.065)$ & $1.62(1.17,2.07)$ & $0.31(-0.18,0.80)$ \\
\hline 30-39 & $(0.072)$ & $3.30(2.61,4.00)$ & $1.51(0.61,2.40)$ & $(0.071)$ & $3.87(3.17,4.57)$ & $1.76(0.98,2.54)$ \\
\hline $40-49$ & $(0.079)$ & $4.12(2.95,5.28)$ & $1.99(0.45,3.53)$ & $(0.078)$ & $4.29(3.27,5.32)$ & $2.83(1.72,3.94)$ \\
\hline \multirow[t]{2}{*}{$50-59$} & $(0.084)$ & $3.19(1.75,4.63)$ & $1.38(-0.46,3.23)$ & $(0.083)$ & $2.62(1.21,4.03)$ & $1.51(-0.03,3.06)$ \\
\hline & Waist-Height Ratio ${ }^{b}$ & & & Waist-Height Ratio ${ }^{b}$ & & \\
\hline $18-29$ & $(0.058)$ & $3.54(3.10,3.98)$ & $0.92(0.02,1.83)$ & $(0.060)$ & $2.76(2.32,3.19)$ & $0.90(0.04,1.76)$ \\
\hline $30-39$ & $(0.067)$ & $3.94(3.24,4.63)$ & $2.60(1.05,4.15)$ & $(0.075)$ & $4.96(4.29,5.64)$ & $2.63(1.18,4.07)$ \\
\hline $40-49$ & $(0.071)$ & $4.73(3.55,5.92)$ & $2.99(0.19,5.79)$ & $(0.079)$ & $5.15(4.16,6.13)$ & $4.69(2.82,6.55)$ \\
\hline $50-59$ & $(0.078)$ & $4.49(3.01,5.96)$ & $4.91(1.70,8.13)$ & $(0.087)$ & $3.68(2.28,5.08)$ & $3.47(0.61,6.33)$ \\
\hline
\end{tabular}

Estimates exclude those on antihypertensive medication. Model 1, estimates from multiple linear regression, adjusted for education and location. Model 2, model 1 plus additional adjustments for ${ }^{a}$ Waist circumference or ${ }^{b}$ Body mass index. SD standard deviation, $\mathrm{Cl}$ confidence interval

with SBP and pulse pressure, and the strength of these associations increases with age [26]. Thus, it is possible that the association between WHtR and hypertension may be augmented by the concomitant increases in abdominal adiposity, reflected by a larger WC, and decreases in height with age. Accordingly, when compared with the other anthropometric measures, WHtR was more strongly associated with both SBP and pulse pressure after the additional adjustment for BMI in the oldest age group. A stronger association between WHtR and pulse pressure among older adults may be of particular relevance, due to the relationship between pulse pressure and higher CVD risk in this subgroup [27, 28].

Several mechanisms that link greater adiposity to elevated blood pressure and risk of hypertension have been proposed $[9,10]$. In light of our findings, mechanisms that relate general adiposity to blood pressure may be of particular relevance for young ( $<30$ years of age) adult women. However, in general, our results suggest that blood pressure may predominantly be associated with abdominal adiposity in adults. Of these mechanisms, increased blood pressure may be the results of oxidative stress, inflammation or physical compression of the kidneys by excess abdominal adiposity, particularly visceral adiposity [9]. For instance, excess visceral and retroperitoneal fat, along with physical compression, may infiltrate the kidneys, leading to impaired pressure natriuresis and hypertension [9]. Nonetheless, further clarification of the potential sex and age related differences in mechanisms linking body fat distribution and blood pressure in India, and elsewhere are warranted.

Our study has some limitations that should be considered when interpreting the results. First, the crosssectional design does not allow for causal inferences to 
- Model 1, adjusted for education and location

- Model 2, model 1 plus adjustment for WC or BMI as indicated

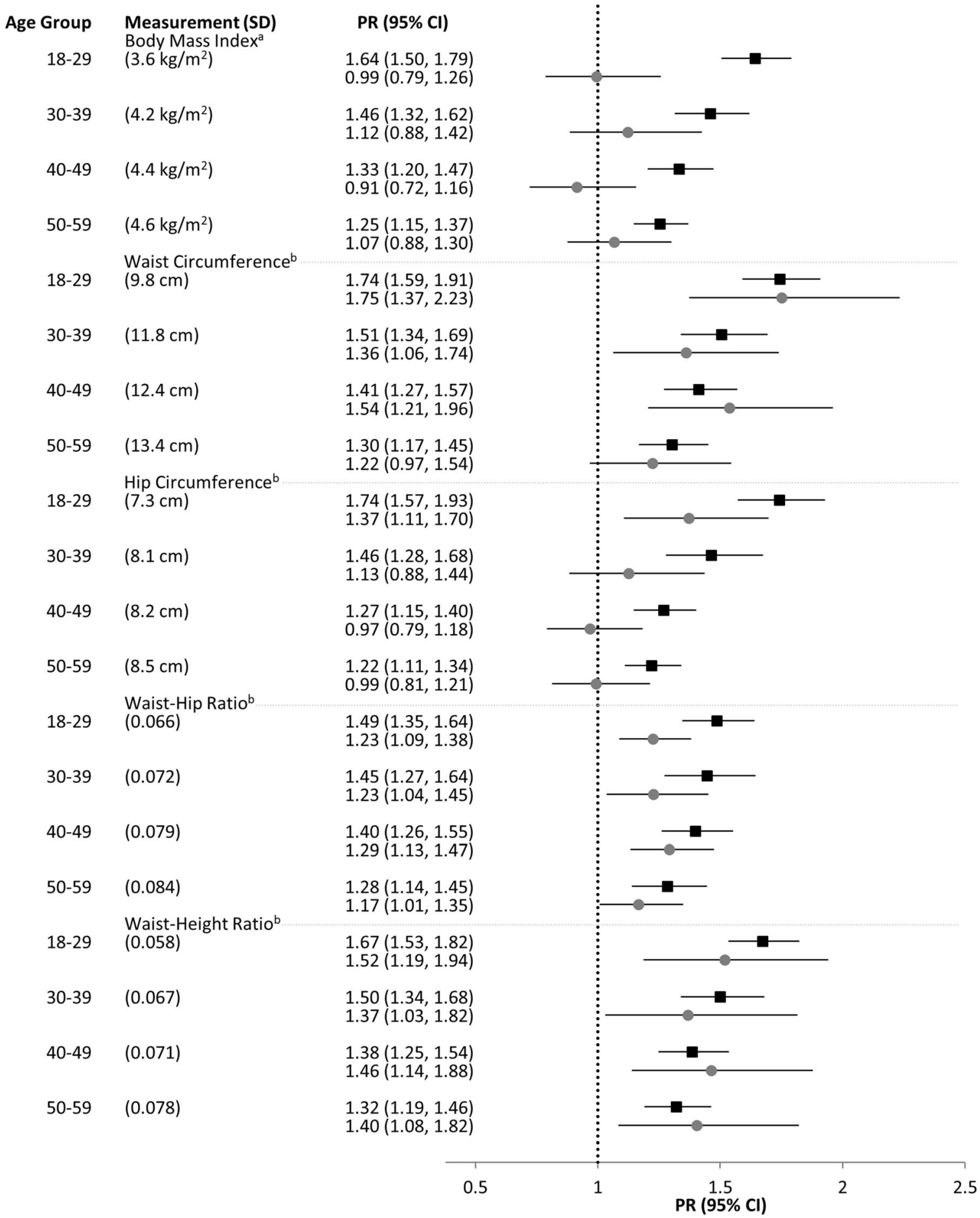

Fig. 1 Prevalence ratios for hypertension per SD of each anthropometric measure among men $(n=3746)$. Additional adjustment for ${ }^{a}$ WC or bBMI. PR, prevalence ratio; WC, waist circumference; BMI, body mass index; SD, standard deviation; Cl, confidence interval 


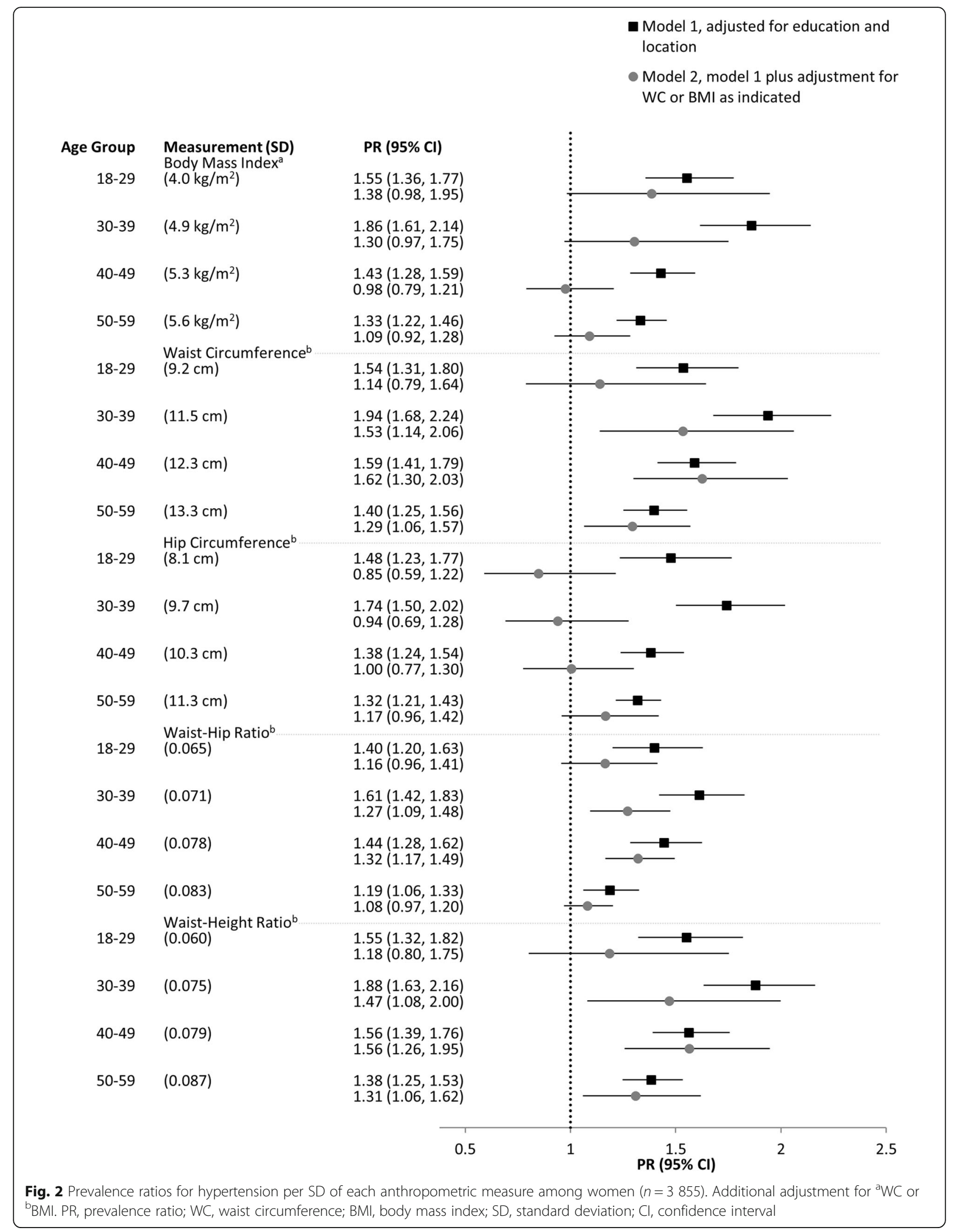


be made about the relationships of adiposity with blood pressure and hypertension. Second, there may be other confounding factors than those available for consideration in our study. However, the largely causal association between adiposity and blood pressure is well established [8]. Thus, it can be speculated that excess adiposity precedes increased blood pressure and hypertension. Moreover, because of the predominantly causal relationship between adiposity and blood pressure, additional adjustment for other potential confounding factors may do little to alter these relationships. Indeed, additional adjustments for alcohol consumption and tobacco use did not materially affect the estimates or alter the observed associations. Third, although effort was made to obtain all circumference measurements on bare skin, some participants did not want to move aside their light clothing, which may be partly due to cultural reasons. Nevertheless, clothing was accounted for by subtracting $1 \mathrm{~cm}$ from measured values. Fourth, even though our study used measured blood pressure, it was only measured during one occasion. In comparison, the use of ambulatory blood pressure monitoring may provide better prognostic value [29]. Despite this, large studies have demonstrated the utility of blood pressure measurements obtained during a single occasion for the prediction of CVD risk [3-6]. Additionally, ambulatory blood pressure monitoring is not as feasible in LMICs, such as India. Lastly, no direct measure of body composition was done. Hence, it is important to keep in mind that although anthropometric measures correlate well with body fat; there is variation in body composition for a given value of any particular anthropometric measure of adiposity [21]. Notwithstanding these limitations, our findings provide guidance for future prospective studies of the relationships between adiposity, its distribution, and CVD risk in India. Further, our study is much larger than previous studies [11-14], and is a sample of the general population of men and women from different regions of India.

\section{Conclusion}

In summary, we provide evidence for the discrete relationships between anthropometric measures of general and central adiposity with various blood pressure components and hypertension in India. Greater emphasis should be placed on measures of central adiposity, such as WC and WHtR for both sexes, than BMI as an adiposity measure in future studies investigating the associations between risk factors for high blood pressure and CVD outcomes.

\section{Abbreviations}

BMl: Body mass index; Cl: Confidence interval; CVD: Cardiovascular disease; DBP: Diastolic blood pressure; HC: Hip circumference; LMIC: Low and middle-income country; PR: Prevalence ratio; SBP: Systolic blood pressure;
SD: Standard deviation; WC: Waist circumference; WHR: Waist-hip ratio; WHtR: Waist-height ratio

\section{Acknowledgements}

This study is supported by grants from the University Health Network (to MF), the Institute for Clinical Evaluative Sciences (to JT), and the University of Toronto (to KT, RM and PJ). The funding sources had no role in the study design; data collection, analysis, interpretation; writing of the manuscript; or decision to submit for publication.

\section{Availability of data and material}

The datasets generated during and/or analysed during the current study are not publicly available because of binding agreements with the government of India.

\section{Authors' contributions}

$K T$ conceived and designed the study, conducted the analyses and drafted the manuscript. PJ supervised the study. All authors contributed to data interpretation, and reviewed the manuscript critically for important intellectual content and approve the final manuscript.

\section{Competing interests}

The authors declare that they have no competing interests.

Consent for publication

Not applicable.

Ethics approval and consent to participate

Ethical approval for the study was obtained from the Institutional Ethical Review Board of St. John's National Academy of Health Sciences. All participants provided written informed consent.

\section{Author details}

${ }^{1}$ Centre for Global Health Research, St. Michael's Hospital, Toronto, ON, Canada. ${ }^{2}$ Dalla Lana School of Public Health, University of Toronto, Toronto, ON, Canada. ${ }^{3}$ Peter Munk Cardiac Centre, University Health Network, Toronto, ON, Canada. ${ }^{4}$ The Heart and Stroke Richard Lewar Centre of Excellence in Cardiovascular Research, University of Toronto, Toronto, ON, Canada. ${ }^{5}$ Department of Family and Community Medicine, University of Toronto, Toronto, ON, Canada. 'Schulich Heart Centre, Sunnybrook Health Sciences Centre, Toronto, ON, Canada. ${ }^{7}$ Institute for Clinical Evaluative Sciences, Toronto, ON, Canada. ${ }^{8}$ Institute of Health Policy, Management and Evaluation, University of Toronto, Toronto, ON, Canada.

Received: 9 September 2016 Accepted: 25 November 2016

Published online: 01 December 2016

References

1. Patel V, Chatterji S, Chisholm D, Ebrahim S, Gopalakrishna G, Mathers C, et al. Chronic diseases and injuries in India. Lancet. 2011;377(9763):413-28.

2. Reddy KS, Shah B, Varghese C, Ramadoss A. Responding to the threat of chronic diseases in India. Lancet. 2005;366(9498):1744-9.

3. Pednekar MS, Gupta R, Gupta PC. Association of blood pressure and cardiovascular mortality in India: Mumbai cohort study. Am J Hypertens. 2009;22(10):1076-84

4. Rapsomaniki E, Timmis A, George J, Pujades-Rodriguez M, Shah AD, Denaxas $\mathrm{S}$, et al. Blood pressure and incidence of twelve cardiovascular diseases: lifetime risks, healthy life-years lost, and age-specific associations in 1.25 million people. Lancet. 2014;383(9932):1899-911.

5. Lewington S, Clarke R, Qizilbash N, Peto R, Collins R. Age-specific relevance of usual blood pressure to vascular mortality: a meta-analysis of individual data for one million adults in 61 prospective studies. Lancet. 2002:360(9349):1903-13.

6. Sauvaget C, Ramadas K, Thomas G, Thara S, Sankaranarayanan R. Prognosis criteria of casual systolic and diastolic blood pressure values in a prospective study in India. J Epidemiol Community Health. 2010;64(4):366-72.

7. Anchala R, Kannuri NK, Pant H, Khan H, Franco OH, Di Angelantonio E, et al. Hypertension in India: a systematic review and meta-analysis of prevalence, awareness, and control of hypertension. J Hypertens. 2014;32(6):1170-7. 
8. Timpson NJ, Harbord R, Davey Smith G, Zacho J, Tybjaerg-Hansen A, Nordestgaard BG. Does greater adiposity increase blood pressure and hypertension risk?: Mendelian randomization using the FTO/MC4R genotype. Hypertension. 2009;54(1):84-90

9. Hall JE, do Carmo JM, da Silva AA, Wang Z, Hall ME. Obesity-induced hypertension: interaction of neurohumoral and renal mechanisms. Circ Res. 2015;116(6):991-1006.

10. Dorresteijn JA, Visseren FL, Spiering W. Mechanisms linking obesity to hypertension. Obes Rev. 2012;13(1):17-26.

11. Venkatramana P, Reddy PC. Association of overall and abdominal obesity with coronary heart disease risk factors: comparison between urban and rural Indian men. Asia Pac J Clin Nutr. 2002;11(1):66-71.

12. Deshmukh PR, Gupta SS, Dongre AR, Bharambe MS, Maliye C, Kaur S, et al. Relationship of anthropometric indicators with blood pressure levels in rural Wardha. Indian J Med Res. 2006;123(5):657-64.

13. Ghosh JR, Bandyopadhyay AR. Comparative evaluation of obesity measures: Relationship with blood pressures and hypertension. Singap Med J. 2007;48(3):232-5

14. Chakraborty R, Bose K, Bisai S. Body mass index and blood pressure among adult Bengalee male slum dwellers of Kolkata, India. J Public Health. 2009;17(5):301-8.

15. Sivanandan V. An assessment of the completeness of death registration in India over the periods 1975-1978 and 1996-1999 under the generalized population model: an analysis based on SRS data. Mumbai: International Institute for Population Sciences; 2004.

16. Whitlock G, Lewington S, Sherliker P, Clarke R, Emberson J, Halsey J, et al. Body-mass index and cause-specific mortality in 900000 adults: collaborative analyses of 57 prospective studies. Lancet. 2009;373(9669):1083-96.

17. Lear SA, Humphries KH, Kohli S, Chockalingam A, Frohlich JJ, Birmingham $\mathrm{CL}$. Visceral adipose tissue accumulation differs according to ethnic background: results of the Multicultural Community Health Assessment Trial (M-CHAT). Am J Clin Nutr. 2007;86(2):353-9.

18. Fox CS, Massaro JM, Hoffmann U, Pou KM, Maurovich-Horvat P, Liu CY, et al. Abdominal visceral and subcutaneous adipose tissue compartments: association with metabolic risk factors in the Framingham Heart Study. Circulation. 2007;116(1):39-48.

19. Li Y, Wei FF, Wang S, Cheng YB, Wang JG. Cardiovascular risks associated with diastolic blood pressure and isolated diastolic hypertension. Curr Hypertens Rep. 2014;16(11):489.

20. Kissebah AH, Krakower GR. Regional adiposity and morbidity. Physiol Rev. 1994;74(4):761-811.

21. Kuk JL, Saunders TJ, Davidson LE, Ross R. Age-related changes in total and regional fat distribution. Ageing Res Rev. 2009;8(4):339-48.

22. Manolopoulos KN, Karpe F, Frayn KN. Gluteofemoral body fat as a determinant of metabolic health. Int J Obes (Lond). 2010;34(6):949-59.

23. Snijder MB, Zimmet PZ, Visser M, Dekker JM, Seidell JC, Shaw JE, Independent and opposite associations of waist and hip circumferences with diabetes, hypertension and dyslipidemia: the AusDiab Study. Int J Obes Relat Metab Disord. 2004;28(3):402-9.

24. van der Kooy K, Leenen R, Seidell JC, Deurenberg P, Droop A, Bakker CJ. Waist-hip ratio is a poor predictor of changes in visceral fat. Am J Clin Nutr. 1993:57(3):327-33.

25. The Emerging Risk Factors Collaboration. Adult height and the risk of causespecific death and vascular morbidity in 1 million people: individual participant meta-analysis. Int J Epidemiol. 2012;41(5):1419-33.

26. Langenberg C, Hardy R, Breeze E, Kuh D, Wadsworth M. Influence of short stature on the change in pulse pressure, systolic and diastolic blood pressure from age 36 to 53 years: an analysis using multilevel models. Int J Epidemiol. 2005;34(4):905-13.

27. Glasser SP, Halberg DL, Sands CD, Mosher A, Muntner PM, Howard G. Is Pulse Pressure an Independent Risk Factor for Incident Stroke, REasons for Geographic And Racial Differences in Stroke. Am J Hypertens. 2015;28(8):987-94.

28. Franklin SS, Khan SA, Wong ND, Larson MG, Levy D. Is pulse pressure useful in predicting risk for coronary heart Disease? The Framingham heart study. Circulation. 1999; 100(4):354-60.

29. Niiranen TJ, Maki J, Puukka P, Karanko H, Jula AM. Office, home, and ambulatory blood pressures as predictors of cardiovascular risk. Hypertension. 2014;64(2):281-6.

\section{Submit your next manuscript to BioMed Central and we will help you at every step:}

- We accept pre-submission inquiries

- Our selector tool helps you to find the most relevant journal

- We provide round the clock customer support

- Convenient online submission

- Thorough peer review

- Inclusion in PubMed and all major indexing services

- Maximum visibility for your research

Submit your manuscript at www.biomedcentral.com/submit
Biomed Central 